\title{
OD KONKRETU RZECZYWISTOŚCI DO POGRANICZA REALNOŚCI - REFLEKSJA WOKÓŁ WCZESNYCH PRAC STEFANA WOJNECKIEGO ${ }^{1}$
}

WERONIKA KOBYLIŃSKA-BUNSCH

\author{
Instytut Historii Sztuki, Wydział Historyczny, \\ Uniwersytet Warszawski \\ The Institute of Art History, \\ Faculty of History, University of Warsaw \\ w.kobylinska@gmail.com
}

\section{KROK, OD KTÓREGO WSZYSTKO SIĘ ZACZĘŁO'}

Rok 1957, Poznań, salon Polskiego Towarzystwa Fotograficznego. Już w progu siedziby mieszczącej się przy ulicy Paderewskiego pod szczęśliwym numerem siedem wyczuwalna jest atmosfera energicznych przygotowań. Wkroczenie w głąb tej nasyconej artystycznym rozgorączkowaniem przestrzeni oznacza zderzenie $\mathrm{z}$ wyjątkowym nagromadzeniem obrazów. Wokół roztacza się heterogeniczna, czarno-biała mozaika gatunków i możliwości interpretacji „nowoczesnego” idiomu. Pięćset dwadzieścia jeden zdjęć polskich autorów, spośród których należy dokonać selekcji ${ }^{2}$. Krytyczne i wnikliwe oko szybko jednak rozpoznaje, że różnorodność jest tylko pozorna.

1 Niniejszy artykuł nie mógłby powstać, gdyby nie serdeczne wsparcie ze strony Pana Profesora Stefana Wojneckiego, który nie tylko zechciał udzielić mi obszernego wywiadu, ale także przekazał na moje ręce liczne materiały i reprodukcje ze swego prywatnego archiwum. Za niezwykle ciepłe przyjęcie oraz podzielenie się ze mną swą wiedzą, doświadczeniem i wspomnieniami niniejszym składam temu wybitnemu Artyście wyrazy serdecznych podziękowań.

2 Ostatecznie na wystawę Krok $w$ nowoczesność (Poznań, 1957) przyjęto sześćdziesiąt sześć prac trzydziestu dziewięciu polskich autorów. Ponadto, zaprezentowano również dziewięćdziesiąt trzy prace czterdziestu dwóch fotografów reprezentujących jedenaście innych krajów: Austrię, Belgię, Czechosłowację, Francję, Holandię, NRD, RFN, Szwajcarię, Szwecję, Wielką Brytanię i Włochy. Zob. Wystawa fotografii artystycznej „Krok w nowoczesność”, Poznań 1957. 
Znakomita większość twórców nie zdecydowała się przekroczyć bezpiecznej, usankcjonowanej w środowisku, piktorialnej ${ }^{3}$ formuły pejzażowej o międzywojennym rodowodzie. Zgłoszono niezliczone sentymentalne widoki natury odbijającej się w taflach wody bądź świetliste impresje przedstawiające kręte polne drogi i aleje, do których tulą się wysokie topole. Zdjęcia te charakteryzowały się celowym zamgleniem konturów, szeroką rozpiętością tonalną i miękkością rysunku. Na tle tych eterycznych, malarskich wizji wyróżniały się dwie prace, które dumnie manifestowały chęć koncentracji na świecie przedmiotów i rzeczywistości konkretu. W przeciwieństwie do znacznej części propozycji przesłanych na ekspozycję Krok $w$ nowoczesność $c^{4}$, prace

3 Piktorializm - kierunek w fotografii artystycznej przeżywający rozkwit pod koniec XIX wieku, którego celem było nadanie zdjęciu charakteru dzieła malarskiego. Zasadniczym postulatem piktorialistów był sprzeciw wobec ostrych, wiernie odwzorowujących rzeczywistość obrazów. W konsekwencji akceptowali oni silną ingerencję w odbitkę fotograficzną, nadającą jej unikatowy charakter. Finalny efekt tej swobodnej wypowiedzi twórczej miał potwierdzać, że fotografia powinna zajmować takie samo miejsce w panteonie sztuki, jak inne dziedziny twórczości plastycznej. W międzywojennej Polsce zapożyczony z Francji piktorializm (w wydaniu propagowanym przez Roberta Demachy'ego czy Constanta Puyo) nabrał szczególnego znaczenia, gdyż stał się istotnym elementem programu sformułowanego przez „ojca polskiej fotografii”, Jana Bułhaka (1876-1950). Koncepcja „fotografii ojczystej” uzyskała zaś w świadomości jemu współczesnych rolę ugruntowanej propozycji teoretycznej. Opiewająca piękno kraju, zaangażowana społecznie fotografia była konsekwentnie popularyzowana $\mathrm{w}$ polskim piśmiennictwie. Solidne podłoże intelektualne zapewniło jej pozycję silniejszą aniżeli ta, która przysługuje (zwykle krótkotrwałej) popularności określonych form stylowych. Szybko postępująca supremacja tego polskiego, „rodzimego” piktorializmu, zasadzającego się na nastrojowo rozmytych wizerunkach pełniących funkcję patriotyczną, nie mogła zostać łatwo przełamana przez obcą, niezaangażowaną fotografię nowoczesną.

4 Wystawa Fotografii Artystycznej Krok w nowoczesność (maj-czerwiec 1957) zorganizowana została przez Polskie Towarzystwo Fotograficzne w Poznaniu i prezentowana była w salonie Polskiego Towarzystwa Fotograficznego (ul. Paderewskiego 7). Funkcję komisarza wystawy pełnił Bronisław Schlabs. W Komisji Kwalifikacyjnej poza Schlabsem zasiadali: Zygmunt Obrąpalski, Fortunata Obrąpalska oraz Janusz Kubanek. 
Stefana Wojneckiego (ur. 1929) cechował brutalny realizm i wyabstrahowanie esencji codzienności. Zaskakująca graficzność, brak operowania miękką plamą walorową, bezprecedensowa dobitność szczegółów - już pierwsze realizacje tego artysty musiały na siebie zwrócić uwagę w środowisku fotograficznym lat 50. XX wieku. Sugestywne, klarowne i wyraziste odbitki wymownie demonstrowały swą tożsamość, zrywając z pokutującym wciąż poczuciem niższości medium fotografii wobec innych dziedzin plastyki. Udział tego wybitnego twórcy w poznańskim fermencie intelektualnym jest nie do przecenienia, gdyż przyczynił się on do krystalizacji postaw awangardowych, tak istotnych dla przemian powojennej polskiej fotografii.

Stefan Wojnecki obalał usankcjonowane sposoby percepcji, w zaskakujący sposób wykorzystując potęgę weryzmu immanentnie wpisanego w medium fotograficzne. Działał zatem na przekór generacji piktorialistów, którzy właśnie precyzjonizm kamery uznawali za bezduszny, automatyczny czynnik wymagający wpierw przezwyciężenia (na przykład za sprawą tak zwanych technik szlachetnych) w celu osiągnięcia obrazu o artystycznym statusie. Odrzucając nastrojowy symbolizm, Wojnecki koncentrował się na odkrywaniu nieoczekiwanych aspektów zwyczajnych przedmiotów. Badał mechanizmy codzienności i penetrował świat rzeczy spowszedniałych. Dwie prezentowane na wystawie Krok w nowoczesność prace jego autorstwa, czyli Grzałka oraz Suwak i kamień, doskonale ilustrują, jak poznański twórca wprawnie żonglował niejednoznacznością kategorii „realizmu”, sięgając po najlepsze tradycje Nowej Rzeczowości (Neue Sachlichkeit). Paradoksalnie, za sprawą bardzo prostych zabiegów, jak choćby odpowiednie zbliżenie soczewki obiektywu do przedmiotów raczej pozbawionych wszelkich metaforycznych konotacji, Wojnecki był w stanie uzyskać wieloznaczne, niemal poetyckie kompozycje.

W przypadku pracy Suwak i kamień Wojnecki wykorzystał swoje fizyczne wykształcenie oraz umiejętności inżyniera, świadomie nadając szklanej kliszy graficznej funkcję negatywu i uzyskując tym samym nadzwyczaj ostry rysunek. Kontury, faktura podłoża, cyfry i oznaczenia - wyłaniają się w sposób ostentacyjny i atakują oko niczym Buñuelowska brzytwa. 


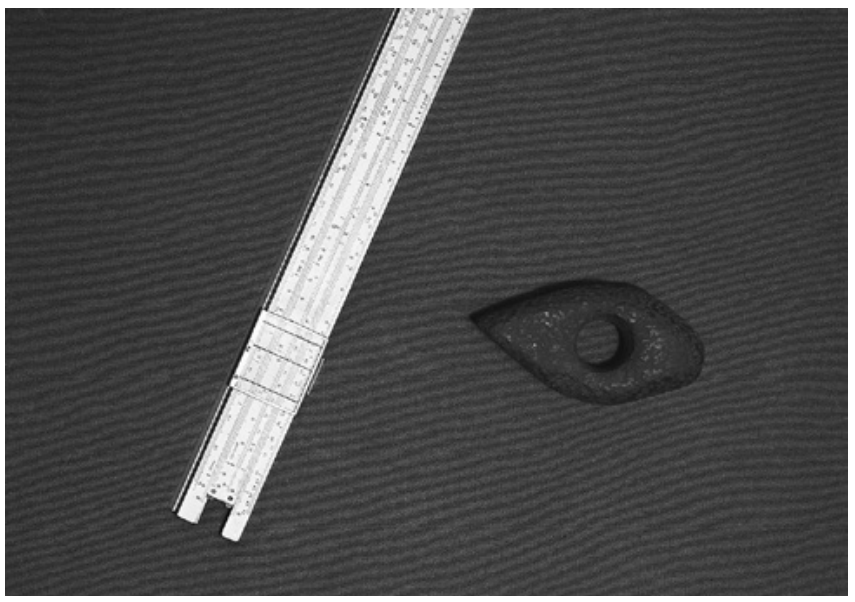

Il. 1. Stefan Wojnecki, Suwak i kamień, 1957 (fotografia-pozytyw) ${ }^{5}$

Z dzisiejszej perspektywy zdjęcie to z pozoru może wydawać się realizacją dokumentacyjną ze względu na szczególny sposób ujęcia: soczewka obiektywu została usytuowana w sposób niemal idealnie równoległy do fotografowanej powierzchni. W rezultacie brak tu przestrzennej głębi, przedmioty statycznie spoczywają na ciemnym tle. W wyobraźni skonfrontowanego z tą pracą odbiorcy uruchamiają się wizje ukazujące pracownię archeologa, który w skrupulatny sposób mierzy i dokumentuje relikt przeszłości. Tymczasem na fotografii tej Wojnecki prehistorycznemu, kamiennemu wytworowi rąk ludzkich przeciwstawił ówcześnie najnowocześniejsze, trudno dostępne narzędzie obliczeniowe - suwak logarytmiczny. Realizuje się tu odwieczny motyw konfrontacji między kulturą, nastawioną na pielęgnowanie tradycji, a nauką - ukierunkowaną na dzień jutrzejszy. Archaiczność spotyka się z symptomem nowoczesności. Zarazem jednak uwidacznia się tu względność wszelkich kategorii odnoszących się do problemu czasu: okazują się one nietrwałe i nieustannie zmienne. Wojnecki problematyzuje jeden $\mathrm{z}$ najdziwniejszych, zdaniem Wisławy Szymborskiej, wyrazów języka. Artysta podziela zdanie polskiej noblistki zawarte w jakże wymownej frazie: „kiedy

5 Wszystkie ilustracje publikujemy dzięki uprzejmości Artysty (przyp. red.). 
wymawiam słowo Przyszłość, pierwsza sylaba odchodzi już do przeszłości"6. Produkt najnowszej technologii wkrótce utraci swą ważność i zostanie wyparty przez bardziej zaawansowane rozwiązania. $Z$ kolei wytwór będący emblematem materialnego dziedzictwa kulturowego stopniowo będzie zyskiwał na wartości ze względu na swój unikatowy charakter świadectwa przemian cywilizacji.

Wykorzystanie ściśle określonych przedmiotów konstytuujących Suwak i kamień - tę nietypową martwą naturę - sugeruje w warstwie narracyjnej możliwość odczytywania tej fotografii przede wszystkim w kontekście opozycji stare - nowe, jednak wątek ów nie wyczerpuje szerokiego wachlarza znaczeń, jaki uruchamia analizowane zdjęcie. Wojnecki demonstruje tu bowiem dojrzały owoc swej refleksji wyrosłej na gruncie dokonań „straży przedniej”, której pierwszym zwiastunem były futurystyczne „słowa na wolności”, stanowiące katalizator rozwoju kolejnych nurtów sztuki XX wieku? Już sam tytuł pracy - w teorii wyłącznie deskryptywny i informacyjny, starający się w neutralny i obojętny sposób opisać przedstawienie - zawiera w sobie pewną awangardową przewrotność ${ }^{8}$. W nazwie tej spotykają się dwa wzajemnie obce i nieprzystające do siebie przedmioty, niczym w owianej legendą dadaistycznej „rozrywce” polegającej na poddawaniu się woli przypadku w zestawianiu ze sobą kolejnych wyrazów czy elementów kolażu9 . Poznański twórca podejmuje $z$ widzem grę i puszcza do niego oko niczym pełni młodzieńczej brawury artyści z kręgu „dada”. W twórczości Wojneckiego wydają się koegzystować różne stylistyki. Artysta podejmuje dialog z awangardą, twórczo reinterpretując będący jej efektem pluralistyczny język obrazowania. Obok dadaistycznej przewrotności można w wypadku tej fotografii również wyczuć echa (przefiltrowanej przez surrealizm) „definicji” piękna autorstwa Comte’a de Lautréamonta, który twierdził, iż piękno to "przypadkowe spotkanie na stole prosektoryjnym maszyny do

${ }^{6}$ W. Szymborska, Trzy słowa najdziwniejsze, [cyt. za:] T. Nyczek, $22 x$ Szymborska, Gdańsk 2000, s. 46.

7 G. Gazda, Awangarda, nowoczesność i tradycja. W kręgu europejskich kierunków literackich pierwszych dziesięcioleci XX w., Łódź 1987, s. 120-125.

8 P. Śliwiński, Poetyckie awangardy. Awangarda przedwojenna, Warszawa 2004, s. 6.

9 H. Richter, Dadaizm, tłum. J. Buras, Warszawa 1986, s. 82-94. 
szycia i parasola"10. Wojnecki podkreśla bowiem nie tylko status i znaczenie poszczególnych przedmiotów, ale przede wszystkim buduje on napięcie między fotografowanymi obiektami, prowokując wyobraźnię widza do odkrywania nieoczekiwanych znaczeń w otaczającej go rzeczywistości. Teza ta rodzi pytanie o to, czy artysta problematyzuje (potwierdzając tezy Petera Bürgera ${ }^{11}$ ), czy może kontynuuje (a raczej - jak ująłby to Stefan Morawski ${ }^{12}$ - dopełnia) działalność ruchów przedwojennych. W niniejszym eseju pozwalam sobie jedynie podkreślić, że Wojnecki podejmuje wątek pewnej nierzeczywistej specyfiki obrazowania; genetyczne związki języka polskiej fotografii powojennej z nurtem surrealizmu stanowią wciąż otwarty i wymagający opracowania rozdział w naszej rodzimej historii sztuki ${ }^{13}$.

Ponadto, przejrzysty świat martwych, pozornie bezwładnie ułożonych przedmiotów nabiera frapującej egzotyki za sprawą pełnej kierunkowych napięć, gruntownie przemyślanej kompozycji. Wzrok odbiorcy rozpoczyna swą wędrówkę $\mathrm{w}$ jednym $\mathrm{z}$ tak zwanych mocnych punktów ${ }^{14}$ fotografii, gdzie usytuowany jest początek jasnego toru matematycznych podziałów i oznaczeń, które diagonalnie przecinają kadr. Scena przypomina migawkowy zapis eterycznego ognia komety, który za chwilę wybrzmi i zniknie, co zapowiada znajdująca się obok kamienna łza. Całość sprawia wrażenie twórczej reinterpretacji symbolu oka o migdałowym wykroju, niepewnie spoglądającego w przyszłość, który to motyw stanowił podstawowy element wizualnej oprawy wzmiankowanej ekspozycji Krok w nowoczesność.

${ }^{10}$ Cyt. za: R. Bréchom, Świat snu, tłum. E. Bieńkowska, „Teksty: Teoria Literatury, Krytyka, Interpretacja” 1973, nr 2, s. 148.

${ }_{11}$ Zob. P. Bürger, Teoria awangardy, tłum. J. Kita-Huber, Kraków 2006.

12 K. Wilkoszewska, W kalejdoskopie awangardowych konstelacji, [w:] Wiek awangardy, red. L. Bieszczad, Kraków 2006, s. 8.

${ }_{13} \mathrm{O}$ inspiracji surrealizmem w dorobku Zdzisława Beksińskiego i Jerzego Lewczyńskiego, którzy - podobnie jak Wojnecki - operowali w latach 50. XX wieku językiem naznaczonym tylko pewnym echem nadrealistycznego rodowodu, pisała między innymi Joanna Kordjak-Piotrowska w szkicu Polska fotografia awangardowa 2. połowy lat 50., [w:] Egzystencje, red. R. Szwander, Warszawa 2005, s. 12.

${ }_{14}$ Zob. informacje o sposobach kształtowania kompozycji w fotografii - podziałach pola obrazu i zasadzie kierunku: P. Wójcik, Kompozycja obrazu fotograficznego, Warszawa 2007, s. 37-41, 64-69. 
Obie prace Stefana Wojneckiego prezentowane na tej jednej z najważniejszych powojennych polskich ekspozycji fotograficznych zasadzały się na antagonistycznych zestawieniach. W przypadku Grzałki elementowi świata techniki artysta przeciwstawił siły natury - dwa podstawowe żywioły. Wijącą się linię błyszczącej przemysłowej konstrukcji otacza bowiem taniec rozedrganych pęcherzyków powietrza, które wibrują „na rozkaz" rosnącej temperatury wody. Bezforemne substancje zostają zmaterializowane na fotografii dzięki wykorzystaniu nieskomplikowanego domowego urządzenia. To, co płynne, bezbarwne i eteryczne, ulega upostaciowieniu; przejrzysta głębia

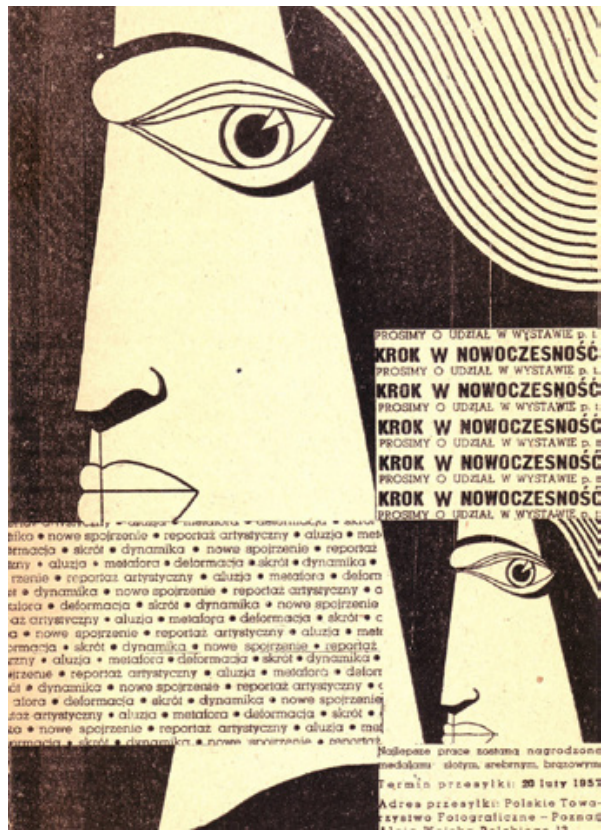

Il. 2. Element identyfikacji wizualnej wystawy Krok w nowoczesność (dzięki uprzejmości Stefana Wojneckiego) nabiera haptyczności. Artyście udaje się ukazać na fotografii wodną przestrzeń i wprawione w ruch powietrze, a zarazem dokonuje on sublimacji znaczenia tytułowej grzałki. Stwarza wizualny poemat na cześć objawu „realności najniższej rangi”15 i w mistrzowski sposób poszerza obszar sztuki fotograficznej o to, co niesłusznie uznawano wcześniej za szpetne czy pozbawione wyrazu. Nieciekawy przedmiot nieoczekiwanie zmienia swój status dzięki gestowi artystycznej legitymizacji. Wojnecki zaciera granice między codziennością a „kulturą wysoką”; wspólnym mianownikiem obydwu opisywanych zdjęć jest potrzeba wykorzystania i przywrócenia znaczenia materii uprzednio zdefiniowanej przez społeczeństwo jako pospolita czy przeciętna.

15 T. Kantor, Teatr śmierci: teksty z lat 1975-1984, oprac. K. Pleśniarewicz, Wrocław - Kraków 2005, s. 17. 


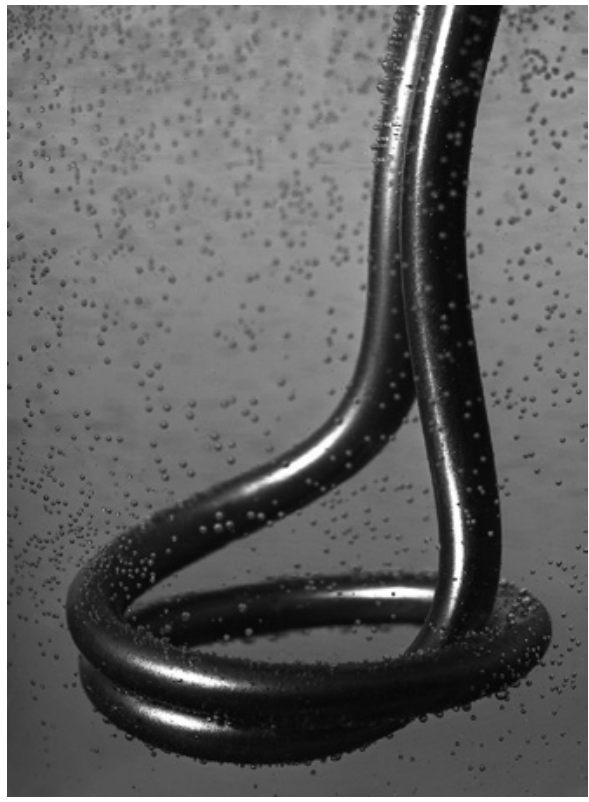

Il. 3. Stefan Wojnecki, Grzałka, 1957 (fotografia-pozytyw)

Fotograf monumentalizuje swój prywatny mikrokosmos, relatywizując nasze percepcyjne przyzwyczajenia. Pozornie nieistotny, błahy i zwykle niezauważalny przedmiot w wizji artysty nieoczekiwanie nabiera dostojeństwa, „mocy sprawczej”, a także może stać się obiektem wizualnego zachwytu. Zacierają się tu granice między strefą $s a$ crum i profanum, podobnie jak w Szarych eminencjach zachwytu Mirona Białoszewskiego. Fotograf podkreśla migotliwą wieloznaczność grzałki, a mistrz pióra - „nieprzecedzonej w bogactwie” łyżki durszlakowej. „Poeta to taki słowiarz, który słowu nie ufa, który atakuje zastane zrosty językowe, rozcina je i organizuje nowe związki słów"16 — słowa Juliana Przybosia dotyczące autora tomu Obroty rzeczy okazują się aktualne także w kontekście śmiałych rozwiązań proponowanych przez Wojneckiego. Artysta „dziwi się” rzeczom, a jego postawa nakierowana jest na zaburzanie apriorycznie pewnych i ustalonych hierarchii, co prowokuje do odwołania się do myśli takich teoretyków, jak np. Bruno Latour - jednostkowe, pozornie nieme obiekty okazują się czynnymi, wywołującymi skutki aktorami sceny społecznej ${ }^{17}$.

\section{ZRYWAJĄC Z KONWENCJAMI}

Pochodząca z 1959 roku praca zatytułowana Drzewo poświadcza, że Wojnecki nie tylko dokonał przewartościowania znaczenia sfery banalnych

16 J. Przyboś, Słowo przedrzeźnione, „Przegląd Kulturalny” 1959, nr 7, s. 8.

17 B. Latour, Przedmioty także posiadaja sprawczość, tłum. A. Derra, [w:] Teoria wiedzy o przeszłości na tle współczesnej humanistyki. Antologia, red. E. Domańska, Poznań 2010, s. 537-539, 549. 
przedmiotów, ale też był w stanie wydobyć nową wizualną jakość z już opatrzonych motywów. Na wzmiankowanym zdjęciu wynurzające się z grubego pnia konary zostają całkowicie wyabstrahowane $\mathrm{z}$ pierwotnie im towarzyszącego kontekstu. Na pozytywie, zdecydowanie większym niż finalnie zamierzony obraz, fotograf za pomocą tuszu ręcznie zamalował (usunął) wszystkie niepotrzebne szczegóły drugiego planu. Dzięki późniejszemu zreprodukowaniu zmodyfikowanej pracy (ale już na mniejszym formacie) artysta świadomie zachował doskonałą jakość, ostrość i wyrazistość form oraz zatarł ślady retuszu. W ten oto sposób fragment natury, dotąd w tak

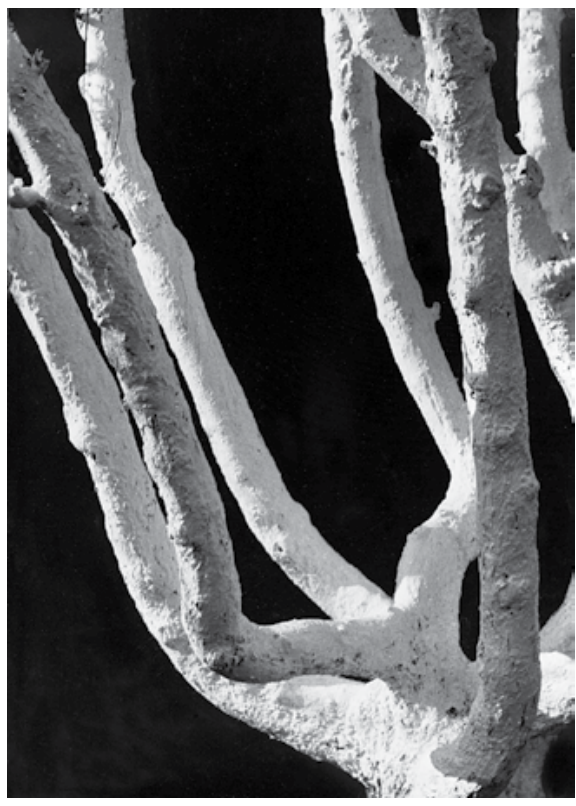

Il. 4. Stefan Wojnecki, Drzewo, 1959 (fotogafia-pozytyw) urokliwy i melancholijny sposób ujmowanej przez polskich fotografików, nabiera przygnębiającego charakteru.

Wojnecki w niezwykle twórczy sposób dokonuje pesymistycznego odwrócenia tradycyjnej symboliki drzewa, zwykle kojarzonego z osią (rozumianą jako źródło i początek) życia ${ }^{18}$. Manualna ingerencja i czarna farba pozwoliły uzyskać silny kontrast pomiędzy głównym motywem a pozbawionym jakichkolwiek informacji tłem, dzięki czemu efekt końcowy stanowi doskonały przykład funkcjonowania tak zwanych obszarów negatywowych - miejsc (pozornie) pustych, niewypełnionych, a jednak niezwykle znaczących dla kreowania plastyki obrazu. Z nicości wynurzają się nagie, bezlistne gałęzie, których kora naznaczona jest szpetnymi wybrzuszeniami. Skonfrontowani z tą wyjątkową wizją przedstawiającą mieszkańca posępnego, pełnego tajemnic lasu, wodzeni niezrozumiałym instynktem - pragniemy dotknąć

18 Zob. M. Eliade, Sacrum, mit, historia, tłum. A. Tatarkiewicz, Warszawa 1974. 


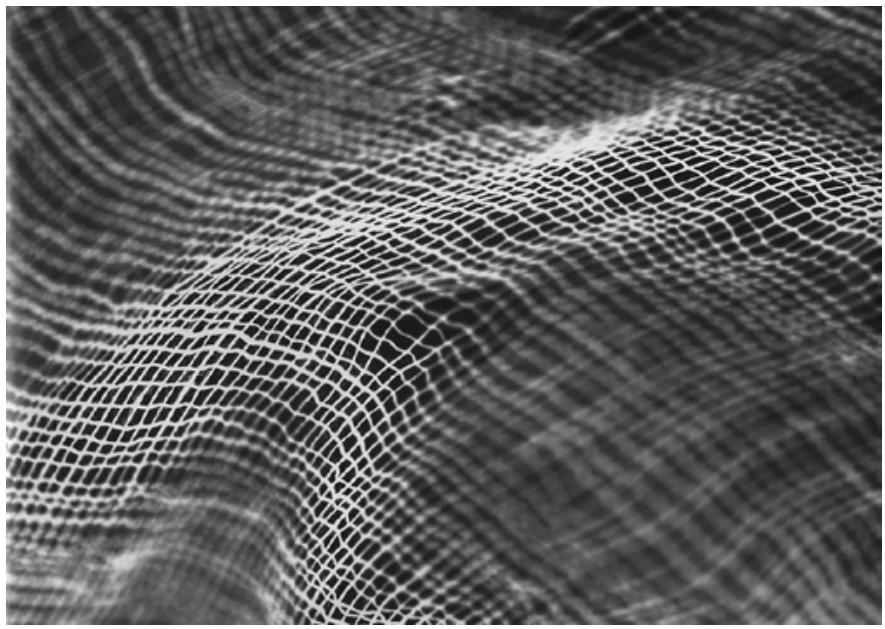

Il. 5. Stefan Wojnecki, Gaza, 1959 (luksografia)

jego szorstkiej faktury. Specyficznie oświetlone, nienaturalnie rozbielone drzewo wydaje się niemal płonąć. Liczne rozgałęzienia winny dawać gwarancję jego żywotności, lecz pozbawione są one przecież kwiecia czy owoców. Najpewniej jest ono już całkowicie uschnięte, niczym wyrzucony na brzeg martwy koralowiec. Czy też może raczej skamieniało ono w bezruchu jak przygarbiony doświadczeniem, sparaliżowany starzec?

Dla wczesnej twórczości Stefana Wojneckiego symptomatyczne wydaje się łączenie awangardowych środków wypowiedzi twórczej z niejednoznaczną symboliką implikującą treści egzystencjalne. Tak rozpatrywać można chociażby pracę Gaza wykonaną w często stosowanej przez artystę non-camerowej technice luksografii (łac. lux - 'światło', gr. gráphein - 'pisać'). W kasetce powiększalnika, zwykle zawierającej negatyw, został zamieszczony tylko fragment materiału, którego obraz był bezpośrednio rzutowany na papier fotograficzny. W ten sposób powstał unikatowy, jednostkowy zapis chwilowego wyglądu przedmiotu - artysta „odcisnął” jego ślad. Obraz został zatem wykreowany bez użycia aparatu, wyłącznie za sprawą manualnych zabiegów i skrupulatnej inscenizacji w ciemni.

Dzięki odpowiedniemu ułożeniu przedmiotu i uzyskaniu małej głębi ostrości fotograf zbudował kilka planów przestrzennych i efektowną 
perspektywę. Wypukłość misternie zagiętej gazy sprawia, że zdaje się ona niemal poruszać czy falować. Wojnecki, rejestrując $\mathrm{w}$ tak niecodzienny sposób kształt pozornie nieefektownego przedmiotu, podejmuje wyrafinowaną polemikę $z$ tradycyjnymi gatunkami fotograficznymi. Penetrowanie włókien, wnikanie w strukturę materiału przywodzi przecież na myśl zbliżenia, w których całość kadru wypełnia naga ludzka skóra ${ }^{19}$. Stanowiące centralny element Gazy wzniesienie przypomina z kolei o typowym dla aktu, subtelnym sposobie pokazywania wyselekcjonowanych, najbardziej pobudzających wyobraźnię aspektów kobiecego ciała. Liryczne ujmowanie nagości na fotografii często prowadziło do wysmakowanego kojarzenia fragmentów anatomicznych z naturalnymi nierównościami terenu Matki Ziemi. Ukazywanie cielesności niejednokrotnie zasadzało się na konotacjach z żeńskim pierwiastkiem ukrytym w panoramicznie ujętym, górzystym pejzażu. Cechujące luksografię odwrócenie naturalnego rozkładu bieli i czerni, a także redukcja półtonów wprowadzają do realizacji Wojneckiego element niepokoju. Przedstawiona przez artystę jasna siatka porów nabiera wanitatywnego charakteru. Zamiast zmysłowej sensualności, Wojnecki z wirtuozerią tworzy metaforyczne odniesienie do ulegającego rozkładowi korpusu. Uczucie to potęguje tytuł pracy, odnoszący się do materiału używanego przede wszystkim w celu tamowaniu krwawień i opatrywania ran. Zawarty w technice luksografii dadaistyczny idiom ${ }^{20}$ zostaje wykorzystany przy uobecnianiu charakterystycznego dla sztuki powojennej wątku biologicznego ${ }^{21}$.

Uzyskane również metodą luksografii Kręgi w bardziej ostentacyjny sposób manifestują swe związki z tematyką dysfunkcyjnego, martwego ludzkiego organizmu. W tej wstrząsającej „lekcji anatomii” człowiek zostaje zredukowany do emblematycznego fragmentu: wewnętrznego miąższu, zwykle ukrytego pod powierzchnią mięśni. Wybrany element kośćca zostaje poddany multiplikacji, przez co tworzy kalejdoskopową feerię form ciasno

19 Zob. np. misterne realizacje Zbigniewa Dłubaka.

20 Metoda ta była znana już w samych początkach fotografii (co potwierdzają prace Williama Foxa Talbota czy Anny Atkins), niemniej dopiero Man Ray w pełni wydobył artystyczny potencjał tej techniki.

${ }^{21}$ Zob. Paris Post War: Art and Existentialism 1944-1954, red. F. Morris, London 1993. 


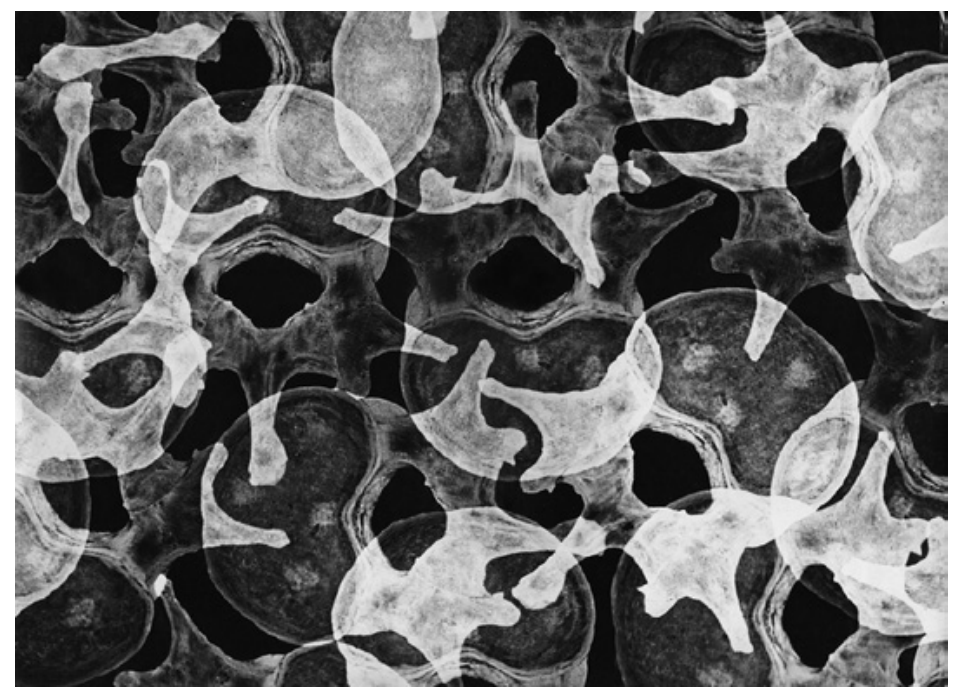

Il. 6. Stefan Wojnecki, Kręgi, 1958 (luksografia)

wypełniających kadr. Ślady ludzkich pozostałości częściowo nakładają się na siebie. Miejsca styku w mniejszym stopniu zostały poddane procesowi naświetlania, i w konsekwencji są one wyraźnie jaśniejsze, przez co niuansują walorowo przedstawienie. Spomiędzy półprzezroczystych tkanek o porowatej strukturze przezierają plamy idealnej czerni zaświetlonego podłoża fotograficznego. Zwielokrotnienie pojedynczego motywu łagodzi „lęk przed pustką".

Łaciński źródłosłów terminu „abstrakcja” (abstractio - 'oderwanie’) nabiera w kontekście tej fotografii szczególnego znaczenia. Kość (mimo że niezaprzeczalnie obarczona biologiczną konkretnością) staje się przyczynkiem do wykreowania wizji zrywającej z tradycyjną kategorią mimesis. Tytułowe kręgi stanowią składową pozbawioną pierwotnego kontekstu, odłączoną - a więc: oderwaną - od człowieka. Niecodzienna konfiguracja spojrzenia kamery niejednokrotnie w historii fotografii była wykorzystywana do tworzenia obrazów nawiązujących do malarstwa nieprzedstawiającego. Za przykład posłużyć mogą choćby dzieła Aarona Siskinda (1903-1991) czy Brassaïa (1899-1984), którzy pokazywali niesamowitość wizualnego potencjału otaczającej człowieka rzeczywistości, sprowadzając 


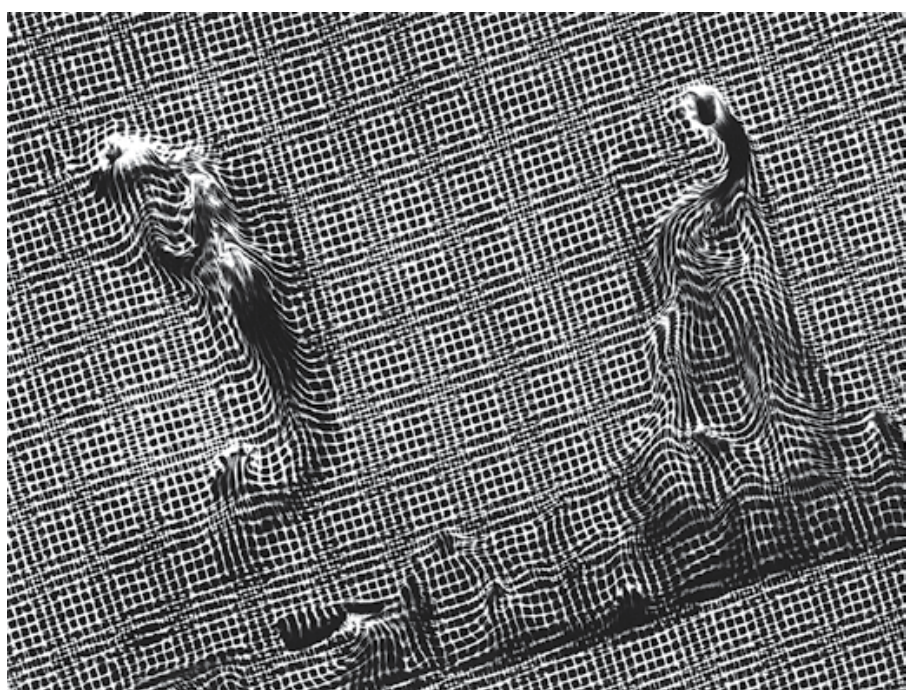

\section{Il. 7. Stefan Wojnecki, Pod powierzchnią, 1958 (fotografia-pozytyw)}

ją do abstrakcyjnego wzoru ${ }^{22}$. Wyraźnie pesymistyczny, egzystencjalny rys tych prac sprawia, iż należą one, pospołu z Kręgami Wojneckiego, do jednej tradycji artystycznej. Siskind i Brassaï, ze znawstwem dobierając i odpowiednio kadrując fragmenty fasad zniszczonych budynków czy pozostałości reklamowych plakatów na płotach, wykorzystywali jednak inne środki wyrazu niż poznański twórca. Wojnecki był bowiem stopniowo coraz bardziej zainteresowany przede wszystkim całkowicie swobodną kreacją obrazu fotograficznego. Dyktowało to wybór luksografii jako metody pracy dla stworzenia tego przejmującego obrazu ludzkich szczątków rozrzuconych na dnie oceanu.

Zdjęcie Pod powierzchnią mogłoby stanowić doskonały przykład transferu i zaadaptowania modernistycznej tradycji abstrakcji ${ }^{23}$ geometrycznej na

22 Do dziś odnajdywanie i wychwytywanie pewnych geometrycznych wzorów z otaczającej rzeczywistości stanowi jedno z klasycznych zadań fotograficznych.

${ }^{23}$ Interpretacje innych prac Wojneckiego operujących tą poetyką, zob. W. Kanicki, Od oscylogramu do estetyki śladu. Abstrakcyjne przypadki w twórczości Stefana Wojneckiego, [w:] Doświadczanie (w) fotografii - Stefan Wojnecki, red. M. Michałowska, M. Piłakowska, Poznań 2015, s. 73-86. 
potrzeby fotografii, gdyż pole obrazu wyraźnie wypełniają misterne, regularne podziały powtarzalnego wzoru. Następuje tu całkowite odstąpienie od reprodukowania otaczającej człowieka rzeczywistości na rzecz unikatowej kreacji alternatywnej kosmogonii. Idealną wizję uporządkowanej, nieomal neoplastycystycznej struktury zakłócają jednak nieregularne rozluźnienia formalnego rygoru, a spektatora niepokoją ekspresyjne wybrzuszenia i wiry. Emulsja szklanego negatywu ze zwielokrotnioną fakturą została miejscowo zwilżona, a następnie podgrzana. Po przechyleniu kliszy substancja ta zaczęła spływać, tworząc nowe, ale jednak kalekie i ułomne organizmy pod powierzchnią tekstury. Manualna ingerencja artysty, polegająca na celowej dezintegracji wykorzystywanego materiału, nosi znamiona autorefleksji nad przebiegiem i charakterem procesu twórczego. Dokonując erozji tradycyjnych metod pracy, twórca stawia pytanie o granice wytrzymałości konwencji samego medium. Wojnecki deklaruje, iż ów wątek w jego twórczości stanowi odpowiedź na autotematyczny nurt sztuki „generatywnej”, poszukującej tożsamości i badającej samą istotę fotografii. Jednocześnie jednak można odważyć się na stwierdzenie, iż poznański fotograf tworzy nową, unikatową dla tego medium ikonografię cierpienia; równie przejmującą jak ta, którą niegdyś wypracował na gruncie plastyki Andrzej Wróblewski za sprawą sugestywnych gwaszy ${ }^{24}$.

Na oczach widza zderzonego z pracą nazwaną przez Wojneckiego Pod powierzchnią rozgrywa się dramatyczny spektakl bez wytłumaczenia. Geneza działania dezintegrującej obraz odśrodkowej siły pozostaje nam nieznana, nie możemy wyczytać jej z samej pracy - liryczne piękno apokalipsy nabiera uniwersalnego charakteru. Statyczny, klarowny język zharmonizowanej geometrii zostaje podważony, a obraz staje się katastroficzną metaforą procesu zniszczenia i destrukcji. Skojarzenie rozedrgania form i ruchu z czynnikiem negatywnym, będącym symptomem zaniku czy rozpadu, widoczne jest również w takich pracach Wojneckiego, jak choćby Nieostrość ruchu (1958), W kosmos (1958) czy Struktura (1962).

24 M. Lachowski, Nowocześni po katastrofie. Sztuka w Polsce w latach 1945-1960, Lublin 2013, s. 238-245. 


\section{PODSUMOWANIE}

Praktyka artystyczna Stefana Wojneckiego przemawia niejako wbrew wykształceniu samego artysty, gdyż odrzuca on postawę racjonalistyczną, którą cechuje przekonanie o sile i możliwościach poznawczych ludzkiego rozumu. Poznański fotograf zdaje się manifestować śmieszność i niewystarczalność precyzyjnych danych naukowych wobec problematyki poznania, wnikania w świat ludzkich emocji. Logika nie jest w stanie sprostać zadaniu wyjaśniania i porządkowania praw funkcjonowania najważniejszych dla człowieczeństwa zjawisk czy kategorii. Wojnecki, dokonując swoistej rewindykacji swobód fotografii, odrzucając wszelkie ograniczenia wolności medium, opisuje świat ludzkich pragnień i niespełnionych nadziei. Jak oswoić i zilustrować tematykę tak trudną, jak sytuacja egzystencjalna jednostki? Wysublimowaną odpowiedzią Stefana Wojneckiego są zdjęcia, które z jednej strony balansują na pograniczu realności, z drugiej natomiast - obierają człowieka i jego emocje za centralny element swej narracji ${ }^{25}$.

\section{Bibliografia}

Robert Bréchom, Świat snu, „Teksty: Teoria Literatury, Krytyka, Interpretacja” 1973, nr 2.

Peter Bürger, Teoria awangardy, tłum. J. Kita-Huber, Polskie Towarzystwo Estetyczne, Universitas, Kraków 2006.

Grzegorz Gazda, Awangarda, nowoczesność i tradycja. W kregu europejskich kierunków literackich pierwszych dziesięcioleci XX w., Wydawnictwo Łódzkie, Łódź 1987.

Mircea Eliade, Sacrum, mit, historia, tłum. A. Tatarkiewicz, PIW, Warszawa 1974. Witold Kanicki, Od oscylogramu do estetyki śladu. Abstrakcyjne przypadki w twórczości Stefana Wojneckiego, [w:] Doświadczanie (w) fotografii - Stefan Wojnecki, red. M. Michałowska, M. Piłakowska, Fundacja 9/11 Art Space, Poznań 2015.

25 Wojnecki problemy te rozwija i prezentuje w nowy sposób w późniejszych pracach konceptualnych, które są głównym przedmiotem zainteresowania badaczy. O przemianach form wizualnych, którymi operował artysta, zob. A. Sobota, Impulsy i pęknięcia, [w:] Stefan Wojnecki - pęknięcia: ku symulacji, oprac. W. Makowiecki, M. Michałowska, M. Pawłowski, Poznań 1999, s. 10-15. 
Tadeusz Kantor, Teatr śmierci: teksty z lat 1975-1984, oprac. K. Pleśniarewicz, Zakład Narodowy im. Ossolińskich, Wrocław - Kraków 2005.

Joanna Kordjak-Piotrowska, Polska fotografia awangardowa 2. połowy lat 50., [w:] Egzystencje, red. R. Szwander, Muzeum Narodowe w Warszawie, Warszawa 2005.

Marcin Lachowski, Nowocześni po katastrofie. Sztuka w Polsce w latach 1945-1960, Wydawnictwo KUL, Lublin 2013.

Bruno Latour, Przedmioty także posiadaja sprawczość, tłum. A. Derra, [w:] Teoria wiedzy o przeszłości na tle współczesnej humanistyki. Antologia, red. E. Domańska, Wydawnictwo Poznańskie, Poznań 2010.

Tadeusz Nyczek, 22 x Szymborska, Tower Press, Gdańsk 2000.

Paris Post War: Art and Existentialism 1944-1954, red. F. Morris, Tate Publishing, London 1993.

Julian Przyboś, Słowo przedrzé́nione, „Przegląd Kulturalny” 1959, nr 7.

Hans Richter, Dadaizm, tłum. J. Buras, Wydawnictwa Artystyczne i Filmowe, Warszawa 1986.

Adam Sobota, Impulsy i pęknięcia, [w:] Stefan Wojnecki - pęknięcia: ku symulacji, oprac. W. Makowiecki, M. Michałowska, M. Pawłowski, Galeria Miejska „Arsenał”, Poznań 1999.

Piotr Śliwiński, Poetyckie awangardy. Awangarda przedwojenna, Wydawnictwo Literackie, Warszawa 2004.

Krystyna Wilkoszewska, W kalejdoskopie awangardowych konstelacji, [w:] Wiek awangardy, red. L. Bieszczad, Universitas, Kraków 2006.

Paweł Wójcik, Kompozycja obrazu fotograficznego, Almapress, Warszawa 2007. Wystawa fotografii artystycznej „Krok w nowoczesnośc”, Spółdzielnia „Grafika”, Poznań 1957.

\section{From Precise Objectivity to the Borderline of Reality - Reflection on Stefan Wojnecki's Early Works}

The main aim of this study is to analyse selected photographs created by Stefan Wojnecki in the 1950s. Chosen materials diversify and enrich the widely accepted image of the artist, who is known primarily for his later conceptual realizations. The essay attempts to characterize those photographs, in which the crucial subject is human individual and his existential 
situation. The basis of the work is primarily the material collected during the interview with the artist himself.

Keywords: neo-avant-garde photography, New Objectivity, New Vision, photogram, photography and metaphor, Polish fine-art photography, post-war photography, Stefan Wojnecki 